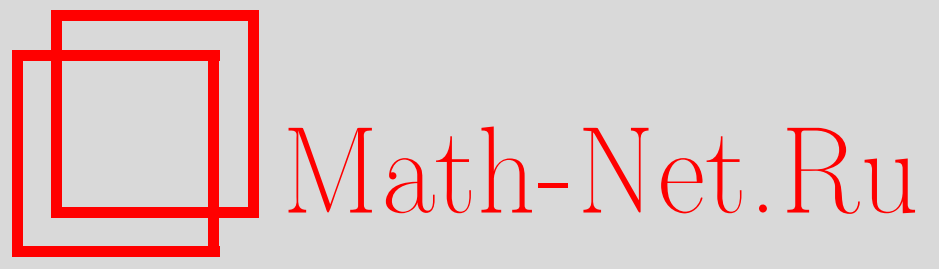

Информация о третьей Колмогоровской студенческой олимпиаде по теории вероятностей, Теория вероятн. и ее примен., 2004, том 49, выпуск 3, 621-623

DOI: https://doi.org/10.4213/tvp216

Использование Общероссийского математического портала Math-Net.Ru подразумевает, что вы прочитали и согласны с пользовательским соглашением

http: //www . mathnet.ru/rus/agreement

Параметры загрузки:

IP : 54.172 .240 .79

26 апреля 2023 г., $17: 33: 23$ 
25 февраля - В. Н. Колокольцов (Москва, Ноттингем). Динамические законы больших чисел для систем взаимодействующих частич.

3 марта - Д. А. Коршунов (Новосибирск). Вероятности больших уклонений эргодических одномерных иепей Маркова в крамеровском случае.

10 марта - Г. И. Ольшанский (Москва). Точечные прочессы и случайные разбиения.

17 марта - С. Б. Шлосман (Москва). Как растет кристалл Изинга?

24 марта - С. В. Пастухов (Москва). О некоторых вероятностно-статистических методах в техническом анализе финансовой математики.

31 марта - Е. А. Жижина (Москва). Спектральный анализ стохастических динамик.

7 апреля - В. В. Вьюгин (Москва). Вероятность: классическая и конструктивная.

14 апреля - А. С. Холево (Москва). О квантовой теории информачии.

21 апреля - заседание, посвященное памяти Игоря Владимировича Гирсанова.

28 апреля - подведение итогов третьей Колмогоровской студенческой олимпиады по теории вероятностей.

12 мая - Д. Н. Карымов (Москва). Об асимптотических разложениях для решетчатьх распределений.

26 мая - 16:20 - Y. Fujikoshi (Hiroshima, Japan). Error Bounds for Edgeworth and Cornish-Fisher Expansions of MANOVA Test Statistics.

26 мая, 18:00 - С. А. Молчанов (Северная Каролина, США). Спектральные бифуркачии для случайных графов.

Координатор семинара в осеннем семестре 2003 года профессор В. В. Сенатов.

Координатор семинара в весеннем семестре 2004 года дочент С. А. Пирогов.

Ученьй секретарь семинара А. В. Селиванов.

\section{ИНФОРМАЦИЯ О ТРЕТЬЕЙ \\ КОЛМОГОРОВСКОЙ СТУДЕНЧЕСКОЙ ОЛИМПИАДЕ ПО ТЕОРИИ ВЕРОЯТНОСТЕЙ}

В ознаменование дня рождения Андрея Николаевича Колмогорова кафедра теории вероятностей механико-математического факультета Московского государственного университета им. М. В. Ломоносова при поддержке Франко-русского института им. А. М. Ляпунова провела третью Колмогоровскую студенческую олимпиаду по теории вероятностей. (Первая и вторая подобные олимпиады проводились в октябре 2001 г. и в апреле 2003 г.; см. Теория вероятн. и ее примен., 2001, т. 46, в. 4, с. 823$824 ; 2003$, т. 48 , в. 2 , с. 428-430. Информация о всех олимпиадах содержится также на сайте кафедры теории вероятностей: http://mech.math.msu.su/probab.)

Олимпиада была проведена 24 апреля 2004 г. раздельно для II и III-V курсов (продолжительность - 4 часа). Оргкомитет констатирует, что в олимпиаде приняли участие 53 студента II курса и 40 студентов III-V курсов механико-математического факультета, факультета ВМиК Московского государственного университета, а также физико-технического факультета Киевского политехнического института, механикоматематического факультета Киевского национального университета, факультета естественных наук и математики Томского политехнического университета и Института естественных наук и экологии г. Москвы. 


\section{Задачи олимпиады}

В скобках после номера задачи указываются курсы, на которых предлагалась данная задача, затем число решивших ее студентов II курса и, наконец, число студентов III-V курсов, решивших эту задачу.

Задача 1. (II-V; 49, 39) Пусть $A$ и $B-$ события такие, что $0<\mathbf{P}(A)<1$ и $\mathbf{P}\{B \mid A\}=\mathbf{P}\left\{B \mid A^{c}\right\}$ ( $A^{c}$ обозначает дополнение к $A$ ). Верно ли, что $A$ и $B$ независимы?

Задача 2. а) (II-V; 31, 30) На некотором вероятностном пространстве заданы случайные величины $X, Y, Z$, причем $Y$ стохастически мажорирует $X$, т.е. $\mathbf{P}\{X \leqslant$ $x\} \geqslant \mathbf{P}\{Y \leqslant x\}$ для любого $x \in \mathbf{R}$. Следует ли отсюда, что $Y+Z$ стохастически мажорирует $X+Z$ ?

б) $(\mathrm{II}-\mathrm{V} ; 6,23)$ Верно ли предыдущее утверждение при дополнительном предположении, что $X$ и $Z$ независимы, а также $Y$ и $Z$ независимы?

Задача 3. (II-V; 33, 26) Сто пассажиров купили билеты в 100-местный вагон. При этом каждому пассажиру было выделено свое место. Первые 99 пассажиров расселись в вагоне случайным образом, так что все 100 ! вариантов рассадки равновероятны. Однако 100-й пассажир решил занять именно свое место. При этом он просит пересесть пассажира, занявшего его место (если оно занято), тот в результате просит пересесть пассажира, занявшего его место (если оно занято), и. т.д. Найти математическое ожидание числа потревоженных пассажиров (100-й пассажир не входит в их число).

Задача 4. (II-V; 14, 16) Имеются 2 игральных кубика с гранями, помеченными числами $1, \ldots, 6$. Можно ли приписать граням каждого из кубиков вероятности выпадения (свои для каждого кубика) так, что при их одновременном бросании сумма выпавших чисел имеет равномерное распределение на множестве $\{2, \ldots, 12\}$ ?

Задача 5. (II; 0) Пусть $X$ и $Y$ - независимые случайные величины, причем $\mathbf{E}|X+Y|<\infty$. Верно ли, что $\mathbf{E}|X|<\infty$ ?

Задача 6. (III-V; 0) Пусть $X_{1}, X_{2}, \ldots$ - независимые одинаково распределенные случайные величины, $S_{n}=X_{1}+\cdots+X_{n}$. Дано, что $\overline{\lim }_{n \rightarrow \infty} n^{-1} X_{n}<\infty$ п.н. Верно ли, что $\overline{\lim }_{n \rightarrow \infty} n^{-1} S_{n}<\infty$ п.н.?

Задача 7. (II-V; 14,19$)$ На окружности выбрано борелевское множество $A$ такое, что $\mu(A)=\frac{2}{3}$, где $\mu$ - равномерная вероятностная мера на окружности (т.е. нормированная лебегова мера). Точки множества $A$ закрашены красным цветом, а точки его дополнения - синим. Доказать, что в окружность можно вписать квадрат, у которого по меньшей мере 3 вершины красные.

Задача 8. (II-V; 0, 1) Пусть $X_{1}, X_{2}, \ldots$ и $Y_{1}, Y_{2}, \ldots$-- две последовательности случайных величин, заданных на одном вероятностном пространстве. Дано, что случайные величины $X_{n}$ и $Y_{n}$ независимы при каждом $n \in \mathbf{N}$ и последовательность $X_{1}+Y_{1}, X_{2}+Y_{2}, \ldots$ сходится по вероятности к нулю. Доказать, что сушествуют числа $a_{1}, a_{2}, \ldots \in \mathbf{R}$ такие, что последовательность $X_{1}-a_{1}, X_{2}-a_{2}, \ldots$ сходится по вероятности к нулю.

Задача 9. (III-V; 3) Пусть $X_{1}, X_{2}, \ldots$ - последовательность случайных величин на некотором вероятностном пространстве $(\Omega, \mathscr{F}, \mathbf{P})$, сходящаяся почти наверное к нулю, причем $\left|X_{n}\right| \leqslant 1$ для любого $n \in \mathbf{N}$. Пусть $\mathscr{G}_{1}, \mathscr{G}_{2}, \ldots-$ под- $\sigma$-алгебры $\mathscr{F}$. Верно ли, что последовательность $\mathbf{E}\left(X_{1} \mid \mathscr{G}_{1}\right), \mathbf{E}\left(X_{2} \mid \mathscr{G}_{2}\right), \ldots$ сходится почти наверное к нулю?

Задача 10. (II-V; 0,0$)$ На борелевской $\sigma$-алгебре $\mathscr{B}$ единичной окружности задана некоторая вероятностная мера $\mu$. Пусть $X, Y$ - независимые случайные точки на окружности, имеющие распределение $\mu$ (т.е. $\mathbf{P}\{X \in A, Y \in B\}=\mu(A) \mu(B)$ для любых $A, B \in \mathscr{B}$ ). Обозначим через $\alpha$ величину угла между точками $X$ и $Y$ (так что $\alpha$ принимает значения в отрезке $[0, \pi])$. Доказать, что $\mathbf{P}\{\alpha \leqslant 2 \pi / 3\} \geqslant \frac{1}{2}$. 


\section{Победители олимпиады}

Разбор задач, вручение призов всем участникам, а также награждение победителей проводились на Большом семинаре кафедры теории вероятностей 28 апреля 2004 r.

\section{Победители среди студентов II курсов}

\section{Первая премия}

Малыхин Юрий Вячеславович - студент II курса механико-математического факультета Московского государственного университета (5.5 решенных задач).

\section{Вторая премия}

Гильмутдинов Эдуард Икрамович - студент II курса механико-математического факультета Московского государственного университета (5 решенных задач).

Москвин Андрей Юрьевич - студент II курса механико-математического факультета Московского государственного университета (5 решенных задач).

\section{третья премия}

Шкляев Александр Викторович - студент II курса механико-математического факультета Московского государственного университета (4.5 решенные задачи).

\section{Победители среди студентов III-V курсов \\ Первая премия}

Гаас Валерий Владимирович - студент V курса механико-математического факультета Московского государственного университета, научный руководитель А. М. Зубков (6.5 решенных задач).

\section{Вторая премия}

Ендовиикий Павел Александрович - студент III курса физико-технического факультета Киевского политехнического института, научный руководитель - А. А. Дороговцев (6 решенных задач).

Клепиков Константин Викторович - студент III курса механико-математического факультета Московского государственного университета, научный руководитель - Ю.Н. Тюрин (6 решенных задач).

Кузнецов Андрей Юрьевич - студент III курса механико-математического факультета Московского государственного университета, научный руководитель Г.И. Фалин (6 решенных задач).

Спиридонов Сергей Викторович - студент III курса механико-математического факультета Московского государственного университета, научный руководитель Г. А. Чечкин (6 решенных задач).

28 апреля 2004 г.
Оргкомитет третьей

Колмогоровской студенческой олимпиадь по теории вероятностей:

чл.-корр. РАН профессор А.Н. Ширяев, аспиранты С. В. Дильман, И.Н. Медведев, А. С. Мищенко, А.В. Селиванов, к.ф.-м.н. М.А. Урусов, к.ф.-м.н. А. С. Черный. 